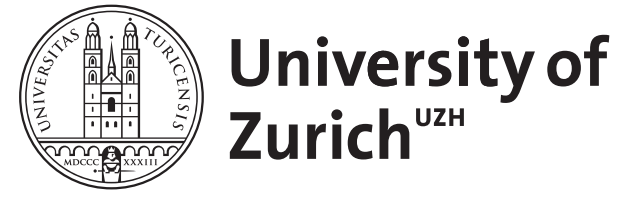

\title{
Arbeit am Absolutismus des Mythos: Mittelalterliche Supplemente zur biblischen Heilsgeschichte
}

\author{
Kiening, Christian
}

Posted at the Zurich Open Repository and Archive, University of Zurich ZORA URL: https://doi.org/10.5167/uzh-92637

Book Section

Originally published at:

Kiening, Christian (2004). Arbeit am Absolutismus des Mythos: Mittelalterliche Supplemente zur biblischen Heilsgeschichte. In: Friedrich, Udo; Quast, Bruno. Präsenz des Mythos. Konfigurationen einer Denkform in Mittelalter und Früher Neuzeit. Berlin: Walter de Gruyter GmbH Co. KG, 35-57. 


\section{Präsenz des Mythos}

\section{Konfigurationen einer Denkform in Mittelalter und Früher Neuzeit}

Herausgegeben von

Udo Friedrich und Bruno Quast

Walter de Gruyter · Berlin - New York 2004.
CHRISTIAN KIENING

(Universität Zürich)

\section{Arbeit am Absolutismus des Mythos}

Mittelalterliche Supplemente zur biblischen Heilsgeschichte

I

Wer von Mythos spricht, tut gut daran, den Begriff pragmatisch zu verwenden, also weder die ebenso faszinierende wie vage Aura des Archaischen zu beschwören noch vorbehaltlos eine der zahlreichen Mythostheorien zu adaptieren, die ihrerseits nicht selten Züge von Mythologien tragen. Die Definitionen sind Legion: Mythos als traditionelle Erzählung, als bildhafte Ausgestaltung natürlicher oder geschichtlicher Vorgänge, als Erklärung, Herleitung oder Autorisierung sozialer Gegebenheiten, als Vergegenwärtigung eines Ursprungs, als Relikt oder Begleiterscheinung ritueller Zusammenhänge, als eigenlogische symbolische Basisform des menschlichen Geistes, als Bewältigung einer übermächtigen, namenlosen, unbegreifbaren Wirklichkeit durch distanzschaffende Verdichtung. Wie auch immer aber man Mythos definieren will, die Definition wird sich beziehen müssen auf die Spezifik von Kulturen, Kontexten und historischen Situationen. ${ }^{1}$ Gerade die je neuen Anläufe, den Mythos als anthropologische, psychologische oder ontologische Universalkategorie zu etablieren, zeigen die Macht einer Denkgewohnheit, mit der sich eine komplex gewordene Rationalität einen vielseitig verwendbaren Gegenpart schafft. ${ }^{2}$ Vom Mythos im Singular zu sprechen kann sinnvoll sein, wenn damit eine phänomenologisch gestützte analytische Kategorie gemeint ist, die nicht

1 Einen begriffsgeschichtlichen Überblick geben die Artikel ,Mythos/Mythologie'. In: Historisches Wörterbuch der Philosophie 6 (1984), Sp. 281-318, und in: Theologische Realenzyklopädie 23 (1994), Sp. 597-665; außerdem: ALEIDA und JAN ASSMANN: ,Mythos'. In: Handbuch religionswissenschaftlicher Grundbegriffe 4 (1998), S. 179-200 (sehr konzise); CHRISTOPH JAMME: ,Mythos'. In: Metzler Lexikon Religion. Gegenwart - Alltag - Medien 2 (1999), S. 515-521; DAGMAR BURKHART: ,Mythos'. In: Enzyklopädie des Märchens 9 (1999), Sp. 1092-1104.

2 GERHART VON GRAEVENITZ: Mythos. Zur Geschichte einer Denkgewohnheit. Stuttgart 1987, bes. Einleitung S. VI-XXVI. 
der bloßen Etikettierung und Klassifizierung von angeblich Mythischem dient, sondern der differenzierenden Analyse von Aspekten und Prozessen kultureller Überlieferung. Zu den Aspekten gehört das je neu zu beobachtende Zusammenwirken mythischer und nicht-mythischer Elemente, zu den Prozessen das im historischen Ablauf zu bemerkende Wechselspiel von Entmythisierung und Remythisierung.

Ein Verständnis von Mythos als phänomenologisch gestützte analytische Kategorie findet in ERNST CASSIRERS Philosophie der symbolischen Formen reiches Anschauungsmaterial. ${ }^{3}$ CASSIRER systematisiert das mythische Denken in Bezug auf Raum und Zeit, Identität und Kausalität, Lebenswelt und Kosmos. Er orientiert sich weniger an den inhaltlichen Dimensionen bestimmter Mythen als an den weltkonstituierenden Formen mythischer Anschauung im Allgemeinen. Er präpariert strukturelle Muster heraus, die allerdings auf einer Homogenisierung heterogener kultureller Bestände beruhen und abendländische Rationalitätstypen zum Maßstab des Vergleichs nehmen. Problematisch ist dieses phänomenologische Unternehmen vor allem im Hinblick auf seine erkenntnispsychologischen und entwicklungsgeschichtlichen Implikationen: Einerseits werden in Kantischer Tradition die Anschauungsformen der mythischen Wirklichkeit als Kategorien des menschlichen Bewusstseins entworfen, andererseits wird das mythische Denken als Form der Protorationalität verstanden und eine historische Abfolge von Mythos und Logos, von Konkretheit und Abstraktheit, von magischer Wirklichkeitsbewältigung und wissenschaftlicher Wirklichkeitsgestaltung nahegelegt. Will man nicht in solche Dichotomien verfallen und nicht den Mythos zu einem scheinbar einheitlichen Typus der Weltkonstitution hypostasieren, ist es nötig, Beschreibungsmodelle einzubeziehen, die der formalen und pragmatischen Dimension des Mythischen Rechnung tragen.

Das semiologische Modell von Roland BARTHES beispielsweise definiert das mythische Prinzip als dreistellige Relation von signifié, signifiant und signification, die sich in der Spannung eines linguistischen und eines metalinguistischen Systems situiert. Eben diese Spannung verleihe dem Mythos seine charakteristische Ğleichzeitigkeit von Statik und Dynamik, von Leere der Form und Fülle des Sinns und erlaube es, Geschichtliches, Künstliches, Wandelbares als Ursprüngliches, Naturhaftes, Unwandelbares erscheinen zu las-

3 ERnst CASSIRER: Philosophie der symbolischen Formen. Zweiter Teil: Das mythische Denken. Berlin 1925, Nachdr. Darmstadt 1964 u. ö.; Auseinandersetzung mit CASSIRER bei HELMUT HolzheY: Cassirers Kritik des mythischen Bewußtseins. In: Über Ernst Cassirers Philosophie der symbolischen Formen. Hrsg von HANS-JÜRG BRAUN/HELMUT HOLZHEY/ERNST WOLFGANG ORTH, Frankfurt a. M. 1988, S. 191 ff.; JÜRGEN MOHN: Mythostheorien. Eine religionswissenschaftliche Untersuchung zu Mythos und Interkulturalität. München 1998, S. 84103; ENNO RUDOLPH: Über einige Schwierigkeiten, sich dem Thema Mythos (philosophisch) zu nähern. In: Rationalitätstypen. Hrsg. von KAREN GLOY, Freiburg, München 1999, S. 129145 , hier S. 134-140 sen ${ }^{4}$ BARTHES öfnet damit den Blick für funktionsanalytische Beschreibungen des Mythischen, für verschiedene Text- und Bildformen, für mikro- wie makrostrukturelle Phänomene, in denen implikationsreiche Überblendungen von Sinnschichten und konnotative Anreicherungen von Bedeutung stattfinden. Doch bleibt dieser Blick sowohl zu allgemein, um das historisch Spezifische, wie zu abstrakt, um das konkret Überlieferte zu erfassen. Reduzierte CASSIRER mit der Universalisierung des Bewusstseins das materiell Vorfindliche zur Anschauungsform, so reduziert BARTHES mit der Verabsolutierung semiotischer Relationen das Vorfindliche zum Demonstrationsobjekt der ideologiekritischen Tätigkeit des ,Mythologen'.

Wo kulturelle Texte im Allgemeinen oder traditionelle Erzählungen im Besonderen zur Diskussion stehen ${ }^{5}$, wird es darum gehen müssen, eine Ebene mittlerer Allgemeinheit zu finden, einen Weg, der sich zwischen der Beschreibung mythischen Denkens auf der einen, der Analyse mythisierender Semiose auf der anderen Seite bewegt und doch beides im Blick behält: Das eine kann fruchtbar sein für die Beschreibung der narrativ entworfenen Welten und deren Regeln, das andere für die Analyse der sprachlichen Operationen, die zumal in jenen Texten besonders komplex sein können, in denen mythische Elemente in hybridisierter Form begegnen. Auf mittelalterliche Texte bezogen bedeutet dies auch, inhaltliche Aspekte mythischen oder mythisierenden Erzählens nicht ganz zu übergehen, formale und pragmatische Aspekte wiederum historisch angemessen zu konturieren.

Inhaltlich kann heißen: Die Erzählung - d. h. ein Text mit narrativer Struktur - betrifft das Verhältnis des Menschen zu übermenschlichen Mächten, sie bezieht sich auf Ursprünge, Übergänge und Gründungsmomente, die mit dem Zeitenabstand nicht an Präsenz verloren haben, vielleicht aber mit Bedeutung angereichert worden sind. Formal kann heißen: Die Erzählung arbeitet mehr mit Bildern und Pathosformeln als mit diskursiven Begründungen, sie lässt kausale und psychologische Motivierungen zugunsten finaler in den Hintergrund treten. Pragmatisch schließlich: Sie steht in sakralen, rituellen oder pararituellen Kontexten, ist eingebunden in soziale Vollzüge und Sinnbildungsprozesse und besitzt deshalb sowohl performative Dimension wie, aufgrund ihres (scheinbaren) Alters oder ihrer (scheinbaren) Evidenz, autoritativen Charakter. Nicht für jeden mythischen oder mythisierenden Text ist das Zusammenspiel

4 Roland Barthes: Mythologies. Paris 1956 u. ö. (dt.: Frankfurt a. M. 1964 u. ö.). Meine knappen Bemerkungen können der semiologischen Komplexität von BARTHES' Modell nicht gerecht werden; einen Versuch, dieses Modell auf mittelhochdeutsche Texte anzuwenden, findet sich bei HARTMUT KOKOTT: Mittelhochdeutsche Mythen. In: Acta Germanica 13 (1980), S. 15-29.

5 Zu Mythos als , traditioneller Erzählung' GEOFFREY STEPHEN KIRK: Griechische Mythen. Ihre Bedeutung und Funktion (engl. 1974). Reinbek bei Hamburg 1987 (rowohlts enzyklopädie 444), S. 20 u. ö. 
dieser Aspekte im gleichen Maße gegeben. Doch dürfte gelten, dass der formale oder der pragmatische Aspekt allein noch nicht genügen, um die Kategorie des Mythischen analytisch sinnvoll zu verwenden. Der formale, von LUGOWSKI im Anschluß an CASSIRER beschrieben ${ }^{6}$, kennzeichnet viele mittelalterliche Texte, ebenso der pragmatische, der aber auch suspendiert oder ins Imaginäre verschoben sein kann.

Zielt man nicht auf eine allgemeingültige Definition oder ein probates Suchraster, entfällt der Zwang, über den Grad an ,Mythizität' eines Textes entscheiden zu wollen. Vielmehr geht es um Kategorien, die es erlauben, Dimensionen narrativer Sinnstiftung zu beschreiben, die sich zwar im Einzeltex manifestieren, aber nicht in ihm allein begründet liegen, ebensowenig aber auf der Ebene der Gattungen und Typen anzusiedeln sind. Daraus ergibt sich die Notwendigkeit, traditionelle Erzählungen als kulturelle Texte zu analysieren, also auf den gesamten Fundus und weiten Horizont mythischen Wissens zu beziehen, der mit dem einzelnen Text aufgerufen sein kann. Die Schöpfungsmythen der biblischen Genesis haben bekanntlich ihren Ort im Rahmen der babylonischen, sumerischen und ägyptischen Schöpfungsmythen. ${ }^{7}$ Der Passionsmythos des Neuen Testaments steht im Kontext hellenistischer Mysterienreligionen und ihrer Vorstellungen von Tod, Wiedergeburt und Apotheose eines Gottes. ${ }^{8}$ Jeweils ist der Mythos, wie BLUMENBERG feststellt, immer schon Rezeption, immer schon Aufnahme und Anverwandlung anderer Mythen. ${ }^{9}$ Von daher bezieht auch das strukturalistische Verfahren seine Berechti-

6 ClEMENS LugowSKI: Die Form der Individualität im Roman (1932). Mit einer Einleitung von HEINZ SCHLAFFER. Frankfurt a. M. 1976 u. ö. (stw 151); Formaler Mythos. Beiträge zu einer Theorie ästhetischer Formen. Hrsg. von Matías MARTínEZ, Paderborn u. a. 1996; JAN-DirK MÚLLER: Der Prosaroman - eine Verfallsgeschichte? Zu Clemens Lugowskis Analyse des ,Formalen Mythos' (mit einem Vorspruch). In: Mittelalter und frühe Neuzeit. Übergänge, Umbrüche und Neuansätze. Hrsg. von WALTER HAUG, Tübingen 1999 (Fortuna vitrea 16), S 143-163.

7 Die Schöpfungsmythen. Ägypter, Sumerer, Hurriter, Hethiter, Kanaaniter und Israeliten. Mit einem Vorwort von MIRCEA ELIADE, Darmstadt 1964 u. ö.; ClAUS WESTERMANN: Genesis 1 11. Darmstadt 1972 u. ö. (Erträge der Forschung 7); HANS-PETER MÜLLER: Mythos - Kerygma - Wahrheit. Gesammelte Aufsätze zum Alten Testament in seiner Umwelt und zur Biblischen Theologie. Berlin, New York 1991 (Beihefte zur Zeitschrift für die alttestamentliche Wissenschaft 200); MichAELA BAUKS: Die Welt am Anfang. Zum Verständnis von Vorwelt und Weltentstehung in Gen 1 und in der altorientalischen Literatur. Neukirchen-Vluyn 1997 (WMANT 74)

8 CARL SCHNEIDER: Geistesgeschichte der christlichen Antike (zuerst 1954). München 1970, S. 44f., 153-157; L. KOEP: Art. ,Consecratio I'. In: Reallexikon für Antike und Christentum 3 (1957), S. 269-283; DIETER ZELLER: Die Menschwerdung des Sohnes Gottes im Neuen Testament und die antike Religionsgeschichte. In: Menschwerdung Gottes - Vergöttlichung von Menschen. Hrsg. von DEMS., Freiburg/Schweiz, Göttingen 1988 (Novum Testamentum et Orbis Antiquus 7), S. 141-176, mit weiterer Literatur.

9 HANS BLUMENBERG: Wirklichkeitsbegriff und Wirkungspotential des Mythos. In: Terror und Spiel. Probleme der Mythenrezeption. Hrsg. von MANFred FunRMANN, München 1971 (Poe- gung: Die Bestandteile des narrativen Inventars grundsätzlich gleichbehandelnd ermöglicht es, die Bedeutung der einzelnen Version des Mythos an den delnd ermöglicht es, die Bedeutung der einzelnen Version des Mythos an den seine Grenzen: Um eine Vergleichsgrundlage zu schaffen, sind Abstraktionen nötig, die wiederum tendenziell die einzelne Version um ihre Eigenart bringen. Diese Eigenart besteht nicht nur in der spezifischen Form der Rezeption und Variation, sondern in der Gesamtheit der semantischen Strukturen, der rhetorischen und pragmatischen Mittel, mit denen ein Text operiert. Erst sie lassen erkennen, wie mythische Elemente funktionalisiert, reflektiert oder transformiert werden, wie eine nicht-diskursive Begründung von ,Bedeutsamkeit' sich vollzieht.

Das gilt nicht zuletzt für die Mythen der christlichen Heilsgeschichte. Weder durch Herausbildung des biblischen Kanons noch durch Dogmatisierung der Glaubenssätze wurden sie obsolet und doch traten sie in Spannung zu nicht-mythischen Begründungen des Heilssystems. ${ }^{11}$ Sie blieben Gegenstand theologischer Interpretation, philosophischer Reflexion und poetischer Imagination, ihre widerständige Bildhaftigkeit blieb Herausforderung für das Universalität beanspruchende dogmatische System, Reibefläche für die an der Botschaft, nicht der Form interessierte Verkündigung der Lehre, Faszinosum für eine auf Vergegenwärtigung zielende Literatur und Kunst. Man verstellt sich den Blick auf die historische Komplexität, wenn man die Grenzlinien zwischen Mythos und Kerygma auf der einen, Mythos und Dogma auf der anderen Seite zu scharf zieht. Die kerygmatische, auf das geschichtlich Faktische bezogene Betonung der christlichen Wahrheit tendiert zwar dazu, Mythisches zu instrumentalisieren, nicht aber gehorcht sie jenem mythenkritischen

tik und Hermeneutik 4), S. 11-66, hier S. 28; DERS.: Arbeit am Mythos. Frankfurt a. M. 1979 passim.

10 CLAUDE LÉVI-STRAuSS: Die Struktur der Mythen (1955). In: ders.: Strukturale Anthropologie l. Frankfurt a M. 1967 u. ö. (stw 226), S. 226-254; ders.: Mythologica I-IV (frz. 1964-1971) Frankfurt a. M. 1971-1975; DERS.: Mythos und Bedeutung. Frankfurt a. M. 1980 (es NF 27); MiCHAEL OpPITZ: Nowendige Beziehungen. Abriß der strukturalen Anthropologie. Frankfurt a. M. ${ }^{2} 1993$ (stw 101), S. 204-326

11 Zum Problem des Mythos im biblischen und frühchristlichen Kontext JACOB TAUBES: Der Zormatische Mythos der Gnosis. In: FUHRMANN (Anm 9), S. 145-156; WOLFHART PANNENBERG: Späthorizonte des Mythos in biblischer und christlicher Überlieferung. In: ebd., S. 473 525; Erste Diskussion: Mythos und Dogma. In: ebd., S. 527-547; zum (christlichen) Mytho im Mittelalter HANS ROBERT JAUSs: Allegorese, Remythisierung und Neuer Mythos. Bemerkungen zur christlichen Gefangenschaft der Mythologie im Mittelalter. In: FUHRMANN (Anm. 9), S. 187-209. JeAN-Claude SCHMitT: Problèmes du mythe dans l'Occident médiéval (zu1988) In: DERS: Le corps, les rites, les rêves, le temps. Essais d'anthropologie médiévale. Paris 2001, S. 53-76; HANS FROMM: „Aufklärung“ und neuer Mythos im Hohen Mittelalter In: DERS.: Arbeiten zur deutschen Literatur des Mittelalters. Tübingen 1989, S. 1-23. 
Existenzialismus, den BULTMANN und andere ihr zuschreiben wollten. ${ }^{12}$ Die dogmatische Verfestigung etabliert zwar vielfältige Spannungen zwischen Begrifflichem und Bildlichem, erst in ihrer zur purifizierenden Systematik geronnenen Verselbständigung aber stellt sie jenes Korsett dar, gegen das BLUMENBERG wiederum den Mythos sich listig behaupten sah. ${ }^{13}$

Präzisere Analyse wird versuchen müssen, die Differenzen zwischen den verschiedenen Typen der Glaubensbegründung weder einzuebnen noch überzubetonen. Sie wird den Blick auf die verschiedenen Formen der Vergegenwärtigung richten müssen, auf die Versuche, das Wirkungspotential des Mythischen im Hier und Jetzt zu nutzen, aber auch es auszudehnen: auf Anlagerungen, Ergänzungen und Weiterdichtungen. Manche von ihnen wiederholen den Grundmythos unter kleinen Ausgestaltungen und Retuschen. Andere setzen ihn voraus und konzentrieren die Erzählung auf das, was vorher ungesagt blieb. Ihr Verhältnis zum Prätext ist also ein supplementäres, ihr Ziel nicht in erster Linie die Arbeit am Absolutismus der Wirklichkeit, sondern die am Absolutismus des Mythos. Terror ist nicht nur, worauf die mythische Erzählung reagiert, sondern auch, was sie ausübt - durch ihre radikale, nicht selten lakonische Prägnanz. Was sie nicht zu erklären und zu begründen brauchte, rückt in den Supplementen ins Zentrum. Die Eigenart der mythischen Erzählung wird sichtbar in ihrer Umschrift.

12 Rudolf BultmanN: Neues Testament und Mythologie. In: Kerygma und Mythos. Hrsg. von HANS WerNer BARTSCH, Hamburg 1948, S. 15-48; DeRS.: Jesus Christus und die Mythologie. Das Neue Testament im Licht der Bibelkritik. Gütersloh 1964 u. ö.; Auseinandersetzung mit Bultmann u. a. bei ROGER ALAN JOHNSON: The Origins of Demythologizing. Leiden 1974; KURT HÜBNER: Die Wahrheit des Mythos. München 1985, S. 324-348; HANS-PETER MÜLLER: Mythos und Kerygma. Anthropologische und theologische Aspekte. In: DERS. (Anm. 7), S. 188-219. RAINER WARNING: Funktion und Struktur. Die Ambivalenzen des geistlichen Spiels. München 1974 (Theorie und Geschichte der Literatur und der Schönen Künste 35) hat be zen die Opposition von Mythos und Kerygma zu sehr als eine starre angesetzt; in diesem Punkt behalten die Einwände FRIEDRICH OHLYs, darauf zielend, das Christentum habe in der Ausmalung von Glaubensinhalten je neu die Grenzen des dogmatisch Annehmbaren umspielt, ihr Recht (Rez. von WARNING, In: Romanische Forschungen 91 [1979], S. 111-141; wieder in: DERS.: Ausgewählte und neue Schriften zur Literaturgeschichte und zur Bedeutungsforschung. Hrsg. von Uwe RUBERG und DIETMAR PEIL, Stuttgart, Leipzig 1995, S. 113-144); Weiterentwicklungen jetzt bei JAN-DIRK MULLLE: Mimesis und Ritual. Zum geistlichen Spiel Weiterentwicklungen jetzt bei JAN-DIRK MÜLLER: Mimesis und Ritual. Zum geistlichen Spiel
des Mittelalters. In: Mimesis und Simulation. Hrsg. von ANDREAS KABLITZ/GERHARD NEUMANN, Freiburg 1998 (Rombach Wissenschaften. Litterae 52), S. 541-571; WALTER HAUG: Rainer Warming, Friedrich Ohly und die Wiederkehr des Bösen im geistlichen Spiel des Mittelalters. In: DERS.: Die Wahrheit der Fiktion. Tübingen 2003, S. 650-663.

13 ENNO RUDOLPH: Mythos - Logos - Dogma. Eine Auseinandersetzung mit Hans Blumenberg. In: Mythos und Religion. Interdisziplinäre Aspekte. Hrsg. von OsWALD BAYER, Stuttgart 1990 (Calwer Taschenbibliothek 3), S. 58-79; JOACHIM VON SOOSTEN: Arbeit am Dogma. Eine theologische Antwort auf Hans Blumenbergs, Arbeit am Mythos'. In: ebd., S. 80-100.
Ich will diesen Prozess an zwei bekannten Fallbeispielen vorführen: der Geschichte des Urmenschenpaars und der des Judas Ischariot, und zwar jeGeschichte des Urmenschenpars einer deutschen Version. Das ist nicht zuletzt weils an einer lateinischen und einer deutschen Version. Das ist nicht der lateideshalb aufschlussreich, weil die deutschen Texte mit der Bibel und der lateinischen Vorlage zumindest zwei Prätexte besitzen, ihr supplementärer Charakter also noch eine zusätzliche Dimension aufweist.

\section{II}

Schon in vorchristlicher Zeit scheinen im Rahmen der Apokryphen und Pseudepigraphen auch Texte in hebräischer oder aramäischer Sprache entstanden zu sein, die über das in der Genesis von den Ureltern Erzählte hinausgingen und weit verbreitet waren. ${ }^{14}$ Eine der ältesten erhaltenen Versionen fand sich unter den in der Bibliothek von Nag Hammadi wieder entdeckten gnostischen Schriften, die sog. Apokalypse Adams, die davon berichtet, wie der Menschenvater in einer Revelation vom Ursprung der eigenen Sterblichkeit erfährt und vater in einer Revelation vom Ursprung den Engeln das wahre Wissen erhält, das er an Seth weitergibt. Gnostische Elemente sind auch in anderen Versionen der Geschichte, griechischen, armenischen, georgischen und slavonischen, nicht ganz getilgt, oft aber marginalinischen, georgischen und slavonischen, nicht ganz getilgt, of aber mas abendlänsiert. So in der lateinischen Vita Adae et Evae, die das Bild, das das abendländische Mittelalter sich vom biblischen Urelternpaar machte, entscheidend seine Entstehung nicht nur der Neugier auf das, was geschah, nachdem Adam und Eva aus dem Paradies vertrieben waren. Er diskutiert am Gegenstand des Ursprungsszenarios zentrale Theologumena von Heil und Erlösung. Er entwirft neu, was vor der Vertreibung geschah und bewältigt so zugleich die mythische Härte, die ein zürnender Gott gegenüber den von ihm geschaffenen Menschen an den Tag legt und die der biblische Redaktor des Sündenfallmythos im Raum stehen ließ. Diese Bewältigung war indes offen für verschiedene narrative Formen. Dementsprechend ist die Vita nicht nur reich, sondern auch in starker Variation überliefert. Jede Abschrift und jede Übersetzung betrieb

14 Die Apokryphen und Pseudepigraphen des Alten Testaments. Übersetzt und hrsg. von EMIL Kautzsch. 2. Bd.: Die Pseudepigraphen des Alten Testaments, Tübingen 1900, Nachdr. Darmstadt 1975, S. 506-528; Altjüdisches Schriftum außerhalb der Bibel. Übersetzt und erläutert von PAUL RIESSLER, Augsburg 1928, S. 138-155 (Apokalypse des Moses), 668-681 (the Books of Adam and Eve. Ed. by GARY A. (Leben Adams und Evas); A Syngsis of th. Books of Ad (Society of Biblical Literature. ANDERSON and MICHAEL E. STONE, Atlanta/Georgia Early Judaism and Its Literature 5); historischer und ikonographischer Überblick zu den Adambüchern bei HANS MARTIN VON ERFFA: Ikonologie der Genesis. Die christlichen Bildthemen aus dem Alten Testament und ihre Quellen. Bd. 1. München 1989, S. 248-314; Forschungsüberblick bei MICHAEL E. STONE: A History of the Literature of Adam and Eve. Atlanta/Georgia 1992 (Society of Biblical Literature. Early Judaism and Its Literature 3). 
durch Zusätze oder Weglassungen, durch Umstellungen oder Verknüpfungen ihre je eigene Arbeit am Mythos. Ich gehe aus von der sog. Gruppe I, bestehend aus lateinischen Handschriften des 9. bis 12. Jahrhunderts. ${ }^{15}$

Der Bezugspunkt des Textes ist gegeben mit dem ersten Satz: Quando expulsi sunt de paradiso. Sündenfall und Vertreibung sind vorausgesetzt. Die Geschichte konzentriert sich auf das nachparadiesische Leben des Urelternpaars: ihre Versuche, durch Buße wieder in den Stand der Gnade zu gelangen, ihr sukzessives Sich-Einrichten in einer Welt des Wandels, der Gewalt und des Schmerzes, ihr Hervorbringen von Nachkommen, ihr schließlicher Tod. Eine Geschichte mit Übernatürlichkeiten, Visionen und Wundern, die an Muster der Heiligenvita anschließt. Eine Geschichte aber auch, die den biblischen Prätext nicht einfach ergänzt, sondern neu konfiguriert. Sie behandelt, was der Bibeltext zwischen der Austreibung aus dem Paradies und der Zeugung Kains und Abels nicht für nötig befunden hatte mitzuteilen. Zugleich führt sie neue Motivationskomplexe ein, entwirft neue Gründungsszenarien und zeigt die alten in neuem Licht. Mit fortschreitender Handlung überlagert sich die Erzählung sowohl mit der nachparadiesischen Bibelerzählung, die sie als Ereignisrahmen nutzt, wie mit der paradiesischen, die sie in Rückblicken einblendet.

Auf der Ebene der Handlung wird ein Zwischenzustand konturiert. Das Urmenschenpaar lebt zeitlich und räumlich weiterhin in Bezug auf das Paradies. Es sehnt sich danach zurückzukehren, es tut Buße, um Gott milde zu stimmen, es verkehrt mit Engeln und Teufel. Von der englischen Speise abgeschnitten, ist es anfangs unfähig, sich überhaupt zu ernähren. Das Paradies bleibt erreichbar, nicht aber betretbar, nur in Visionen wird Adam und Seth der unmittelbare Anblick Gottes zuteil. Doch eben diese Situation erlaubt auch eine im Göttlichen wurzelnde Begründung von Praktiken und Institutionen: Durch den Erzengel Michael versieht Gott Adam mit Pflanzensamen und zeigt ihm, ,wie er die Erde bearbeiten und bebauen solle, damit sie Früchte hätten, von denen sie und ihre Nachkommen leben könnten"; in einigen Handschriften lehrt er auch Eva, „wie sie ihren Sohn stillen und ernähren solle“; durch Michael und Uriel erhalten die Nachkommen mit Adams Tod zugleich ein Modell für künftige Riten - ,Wie ihr es gesehen habt, so begrabt eure Toten. “16

is Vita Adae et Evae. Hrsg. und erläutert von WILHELM MEYER, München 1878 (Abhandlungen der Philosophisch-Philologischen Classe der Kgl. Bayerischen Akademie der Wissenschaften 14), S. 187-250; Texte nach anderen Handschriften bieten JOHN HENRY MOZLEY: The Vita Adae. In: Journal of Theological Studies. Old Series 30 (1928), S. 121-149; GERHARD EIS: Beiträge zur mittelhochdeutschen Legende und Mystik. Untersuchungen und Texte. Berlin 1935 (Germanische Studien 161), S. 241-255.

16 Vita, ed. MEYER, S. 228 (§ 22): misit dominus deus per Michahel angelum semina diversa et dedit Adae et ostendit ei laborare et colere terram, ut habeant fructum, unde viverent ipsi et omnes generationes eorum [angelus vero domini ostendit Evae, qualiter puerum lactare deberet et nutrire]; ebd., S. 242 (\$ 48): sicut vidistis, similiter sepelite mortuos vestro
Die Klage, die zu Beginn des Textes dem Verlust eines zu spät begriffenen Idealzustands galt, gilt am Ende dem Verlust des in seiner Gottzugewandtheit Idealzustands galt, gilt am Ende dem Verlust des in Jahre alte, dem Tod nahe unerschütterten Stammvaters. Zwar erzählt der 930 Jahre alte, dem Tod nahe Adam, von Seth gefragt, was Schmerz sei, die Geschichte des Sündenfalls, die Weichen für die Zukunft der nächsten Generationen aber sind schon gestellt. Werwandelt sich die rückwärts

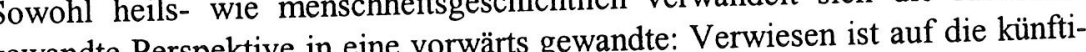
gewandte Perspektive in eine vorwarts gewandte: Verwiesen ist auf die kunftge Erlösung Adams und des Menschengeschlechts aus dem Bann des Todes (mit dem Jüngsten Gericht in 5500 Jahren), aber auch auf die Ausbreitung der (mit dem Jüngsten Gericht in über die Erde. Der Text beschreibt die Über62 noch lebenden Adamskinder über die Erde. Der Text beschreibt die Ubermittlung von Erfahrungen über den Wechsel von Generationen hinweg - und dies mit Hilfe der Schrift: Am Ende trägt Eva, die durch den Erzengel Michae dies mit Hilfe der Schrift: Am Ende trägt Eva, die durch gehört hat, ihren Söhvon künftigen Katastrophen des Menschengeschlechts gehört hat, ihren Söhnen auf, ihr und Adams Leben auf Tafeln festzuhalten, einmal auf solchen von Stein, die das Wasser, und einmal auf solchen von Lehm, die das Feuer zu überstehen vermögen.

Während in der biblischen Genesis das urgeschichtliche Desaster des Menschen und die folgende, Geschichte aufspannende Kette von Genealogien in her Vita die Ereignisse des harter Fügung nebeneinander stehen, werden in deschichte des Menschen erzählt: Anfangs konsequent als Elemente einer Geschichte des Menschen erzăhl emotionalisiert und dramatisiert, zum paradigmatischen Bericht über den gefallenen und doch hoffenden Menschen geordnet. Wichtigstes Stilmittel ist die Ber Figurenperspektive. Fast alle Elemente der Geschichte werden im Dialog oder Monolog geboten, entscheidende Punkte der Vorgeschichte im im Dialog oder Monolog geboten, entscheidende Punkte der Vorgeschichte im Rückblick. Seinen Kindern erzählt Adam, in anderen Fassungen durch Eva ergänzt, von den fatalen Geschehnissen im Paradies. Ihrerseits bekommen Adam und Eva erzählt, was diesen Geschehnissen, ja sogar ihrer eigenen Erschaffung vorausliegt. Eine pointierte Situation: Buße tuend im Jordan lässt Eva sich wieder vom Teufel täuschen, diesmal kommt er in der Erscheinung eines Engels und verführt sie dazu, den Fluss schon vor Ablauf der vorgesehenen Bußzeit zu verlassen. Als sie dank Adam den Versucher erkennt, bricht sie in Klage aus: „Wehe dir, Teufel, warum bekämpfst du uns ohne Grund? Was hast du mit uns? Was haben wir dir getan, daß du uns so listig verfolgst?"

Das ist das Stichwort, den Teufel selbst berichten zu lassen - von der ErDench, das später geschaffeschaffung des Menschen, dem Unwillen mancher dem Sturz der Engel, ihrem ne Ebenbild Gottes anzubeten, der biblische Fall seine Erklärung. Die

17 Ebd , S. $224(\S 11)$ ve tibi, diabole, quid nos expugnas gratis? quid tibi apud nos? aut quid tibi fecimus, quoniam dolose nos persequeris?

18 Zur Rolle des Teufels Nell ForsYTH: The Old Enemy. Satan and the Combat Myth. PrinceZur Rolle Jersey 1987, S. 232-242; zum Engelsturz JOHANN MICHL: Art. ,Engel’. In: Realleton, New Jersey 
Kette der Ursachen verlängert sich zurück bis zu einem Punkt, der zwar selbst nicht erklärt wird, aber auch nicht erklärt zu werden braucht. Das mythische Prinzip, vom Dogma aufgegriffen, zielt darauf, Ursprünge von Ursprüngen zu erzählen und als solche $\mathrm{zu}$ setzen, d. h. die Möglichkeit eines regressus ad infinitum im gleichen Moment, in dem sie sich andeutet, auszuschließen. Warum Gott den Menschen nach seinem Ebenbild schuf und den Engeln befahl, ihn anzubeten - dafür gibt es keine Begründung. Der Text erzählt nicht nur chronologisch, sondern auch logisch von der Existenz des Menschen her. Die Finalität der Ereignisse im Blick auf die sich in der Passion vollziehende Nobilitierung des Menschen lässt er anders als andere Texte aus dem Spiel. Stattdessen entwirft er im Einklang mit jüdischer Apokalyptik Züge eines kosmischen Dramas, das den Gegner als eine Figur der Nähe begreift ${ }^{19}$, die Gefahr eines gnostischen Mächtedualismus aber abwehrt: Der Konflikt zwischen Gott und den Engeln wird nicht als objektives Faktum geboten, sondern als subjektiver Bericht des Hauptbetroffenen, und dieser erscheint in der Handlungsgegenwart der Geschichte nicht als gleichwertiger Gegner des Höchsten: Wo sich die Menschen, vom Teufel geplagt, an Gott mit der Bitte um Hilfe wenden, muss diabolus postwendend das Weite suchen.

Die Vita bietet also Erklärungen für im Bibeltext unerklärt Gebliebenes, sie stellt Kausalitäten her zwischen unverbunden Gebliebenem, sie mildert das undurchschaubar und maßlos wirkende Handeln Gottes durch Verschiebungen der Perspektive. Gleichzeitig zielt sie auf Anteilnahme am Schicksal des Urelternpaars und reagiert auf Fragen, die sich an den Bibeltext stellen konnten, zum Beispiel, warum Abel Schafhirt und Kain Ackerbauer wird. Die Antwort: Ein unheilvoller Traum Evas bei der Geburt Abels habe dazu geführt, die beiden Brüder räumlich und in ihren Tätigkeitsfeldern zu trennen - an der Geschichte der Söhne, am Grund des Brudermords, über den die jüdische und frühchristliche Tradition spekulierte, ist der Text nicht interessiert. Er rationalisiert das Mythische und hält gleichzeitig an dessen Sinnpotential fest. Er verweigert sich einer mythischen Opferlogik - der Gedanke, den zürnenden Gott gnädig zu stimmen durch ein Menschenopfer, hier das Opfer des Sündenbocks Eva, wird Eva selbst in den Mund gelegt und dann von Adam explizi zurückgewiesen - und vermehrt doch andererseits mythische Erzählelemente. Zwischen dem Teufel als Gegner und den Engeln als Helfern bewegt sich der Mensch im Spannungsfeld übermenschlicher Mächte. Der ansatzlose Zorn Gottes und des Teufels steht neben den sentimentalen Affekten der Menschen. Die Gestirne verfinstern sich und dienen als Übermittler von Botschaften, die

schen Engeln und Menschen. Untersuchungen zur rabbinischen Engelsvorstellung. Berlin, New York 1975; HANS BluMENBERG: Matthäuspassion. Frankfurt a. M. 1988 (Bibliothek Suhrkamp 998), S. 119-121; ElaINE PAGELS: Satans Ursprung (engl. 1995). Frankfurt a. M. 1998 (st 2868), passim.

19 Pagels (Anm. 18), S. 84f.
Wasser des Tigris bleiben bei Adams Buße stehen, die Tiere umringen den Menschenvater, Kain kann nach seiner Geburt sofort laufen und seiner Mutter einen Halm bringen - auch dies wohl ein ätiologisches Moment, bezogen auf Evas Satz in der Genesis: possedi hominem per Dominum $(4,1)$.

Die mythischen Elemente werden auf solche Weise funktional: Sie dienen der Profilierung einer Welt, die als Vorzeitwelt erscheinen soll, und dienen gleichzeitig der Profilierung einer Erzählung, die bereits einer anderen Rationalität gehorcht, aber ihre eigene Distanz zu den Ursprüngen kaschiert. Die Ambivalenz des Endes macht dies sichtbar: Die vorliegende Geschichte erweist sich als gegründet in einer scheinbar mehrfach gesicherten Urschrift, von der aber genau genommen doch nichts die Zeiten überdauert haben kann. Eva missversteht offensichtlich die Ankündigung des Engels von zwei aufeinander folgenden Strafgerichten, sie lässt Tafeln anfertigen, die zwar jeweils die eine der beiden Katastrophen überstehen, spätestens in der andern aber zugrunde gehen. Es bleibt also offen, auf welche Geschichte der gegenwärtige Text sich tatsächlich stützt.

Eben dies bot aber auch, so darf man vermuten, die Möglichkeit, am Text beständig weiterzuarbeiten. Die Vita Adae et Evae hatte zwar autoritativen, aber nicht kanonischen Status. Sie blieb offen für Veränderungen verschiedener Art, Veränderungen, die durchaus nicht nur die weitere Entfernung von der Bibel, sondern auch den näheren Anschluss an sie suchten ${ }^{20}$ Einige Handschriften fügen am Beginn des Textes zwei Kapitel hinzu, die Motive aus Genesis 3 aufnehmen und damit die Vita enger mit der Bibelerzählung verknüpfen. Andere setzen am Ende des Textes hinzu, wie Salomon die von Seth angefertigten Tafeln findet, und beheben damit das Problem der Übermittlung der authentischen Geschichte. Wieder andere lassen die Vita in eine Geschichte des Kreuzholzes münden. Eine dieser letztgenannten Handschriften war die Vorlage der vielleicht im 14. Jahrhundert entstandenen mittelhochdeutschen Bearbeitung Lutwins. ${ }^{21}$

20 Zu den mittelhochdeutschen Versionen Brian MURDOCH: The Recapitulation of the Fall. Amsterdam 1974 (Amsterdamer Publikationen zur Sprache und Literatur 11); DERS.: Ein deutsches Adambuch und die Adamlegenden des Mittelalters. In: Deutsche Literatur des späten Mittelalters. Hrsg. von WOLFGANG HARMS/L. PETER JOHNSON, Berlin 1975, S. 209-224; DERS.: Hans Folz and the Adam-Legends. Texts and Studies. Amsterdam 1977 (Amsterdamer Publikationen zur Sprache und Literatur 28); DERS.: Adam's Grace. Fall and Redemption in Medieval Literature. Woodbridge 2001; außerdem BOB MILLER: Eine deutsche Versübersetzung der lateinischen Vita Adae et Evae in der Weltchronik Heinrichs von München. In: Studien zur Weltchronik Heinrichs von München. Bd. 1: Überlieferung, Forschungsbericht, Untersuchungen, Texte. Hrsg. von HORST BRUNNER, Wiesbaden 1998 [1999] (Wissensliteratur im Mittelalter 29), S. 240-332 mit Ausgabe und reichen Literaturangaben auch zur lateinischen Fassung.

21 Ichen Fitiere nach der Ausgabe von MARY BESS HALFORD: Lutwin's Eva und Adam. Study Text - Translation. Göppingen 1984 (GAG 401), S. 101-236. 
Markanter Zug des Textes oder auch schon seiner Vorlage ist die Umstellung der Erzählordnung zugunsten der Chronologie. Der Text beginnt mit der Erschaffung der Welt und des Menschen, dem Neid der Engel und dem Sündenfall, der später ein weiteres Mal aus der Perspektive Adams erzählt wird. Ein heilsgeschichtlicher Bogen spannt sich vom innergöttlichen Schöpfungsentschluss bis zum menschheitsgeschichtlichen Neubeginn nach der Sintflut ein stringentes Heilswerk, dessen Ordnung sich am Ende im Wiederzusammenkommen der von den paradiesischen Bäumen stammenden Zweige und im Ausblick auf die in Christus verkörperte Heilserneuerung manifestiert. Konsequenterweise ist in diesem Rahmen von der Sicherung der Ursprungsgeschichte nicht die Rede. An der Stelle der Überlieferung der Schrift steht die Überlieferung der Zweige, an der Stelle der von Menschenhand stammenden Urkunde das aus dem Paradies selbst stammende Zeichen des Heils. Lutwin erzählt die Geschichte von Adam und Eva vor dem Hintergrund einer langen Auslegungstradition. Er schickt deshalb den Menschenvater nach seinem Tod in die Hölle, lässt aber Gott selbst erklären, wie sein Zorn zum Erliegen kommen und er die Fesseln der Hölle sprengen werde.

Im eigentlichen Vitenteil entspricht die Handlung weitgehend der lateinischen Fassung. Nur die descriptiones sind gelegentlich erweitert, zum Beispiel bei den protokulturellen Tätigkeiten des Urmenschenpaars und bei ihren Affekten. Größeres Gewicht erhalten die Klagen beim Tod Adams, und gänzlich neu ist die Rolle der Minne. In der Genesis sind die erste sexuelle Begegnung von Adam und Eva, Empfängnis und Geburt des ersten Sohnes bekanntlich in einem einzigen lakonischen Satz zusammengefaßt $(4,1$ : Adam vero cognovit Havam uxorem suam quae concipit et peperit Cain). In der Vita gibt es zwar reichere Beziehungsnuancen, wie Eva aber schwanger wurde, wird nicht näher ausgeführt. Hier setzt Lutwin ein. Als Adam nach Absolvierung seiner Bußzeit aus dem Jordan kommt, überwältigt ihn ein bisher unbekanntes Gefühl: Das er des nit erwenden kunde, | Er müste begynnen an der stunde | Mit Eua seltzammer gedat, | Als nach menschlich nature hat (v. 1516-1519). Die zum Vorschein kommende Natur ist aber offensichtlich bei Eva im Übermaß ausgeprägt: Sie zieht "das neue Liebesglück dem Paradiesesglück vor und handelt sich damit Adams Schelte ein; er würde für ein Ästlein aus dem Paradies auf die Liebe verzichten. Mit diesem Dissens motiviert der Text die folgende durch die Vita vorgegebene räumliche Trennung von Adam und Eva. Zugleich deutet er voraus auf die am Ende erzählte Geschichte der Zweige der Paradiesesbäume.

Die Treue zur Vorlage schließt also Versuche zur Plausibilisierung und Homogenisierung nicht aus. Das Verhältnis des Textes zur biblischen Geschichte ist zwar eindeutig ein supplementäres, zugleich aber auch ein ordnendes und kommentierendes. Lutwin erzählt nicht einfach die Geschichte von Adam und Eva. Er macht das Erzählen zu einem Akt didaktischer Heilsver- mittlung. Verwiesen ist immer wieder auf die Genesis und andere Quellen, unterbrochen der Fortgang der Handlung durch allegorische Deutungen und ironische Bemerkungen, durch Heranziehen von Exempelfiguren, Einschub einer Memento-mori-Predigt und Anrede des (weiblichen) Publikums. Nicht selten weiten sich die Digressionen zu seitenlangen Kommentaren, die auch theologische und exegetische Probleme berühren. Zurückkehrend zur narrativen Chronologie, war ja noch nicht die schwierige Aufgabe gelöst, der eigentümlichen Geschichte des Verhältnisses von Gott und Mensch einen Sinn zuzuweisen, einen Sinn, der überdies nicht bloß von Menschen ausgedacht sein soll. Der Text liefert deshalb Begründungen sowohl für die Entstehung der Schöpfung wie für Fall und Erlösung des Menschen. Die Muster sind bekannt: die Schöpfung als notwendige Manifestation der zur Selbstentfaltung drängenden Güte der Gottheit, der Sündenfall als Paradigma, an dem diese Güte in extremster Weise zum Vorschein kommen kann. Damit war aber auch das zentrale Problem der göttlichen Providenz aufgeworfen. Lutwin betont Gottes Vorherwissen bezüglich Adams Sünde und lässt doch den Teufel scheinbar autonom agieren. Der Reiz, die Geschichte als Handlung zu erzählen, und das Bedürfnis, sie zu erklären, treffen immer wieder spannungsvoll aufeinander. Deutlich ist das Vergnügen, einen agierenden Gott zu zeigen: zornig, wenn er es mit den Intrigen des Teufels und den Verfehlungen der Menschen zu tun hat, barmherzig, wenn er dem sterbenden Adam sine götliche hant uff das houbet legt (v. 3124f.) und mitsamt seinen Scharen den Leichenzug bildet. Deutlich ist aber auch: Die Fragen haben sich vermehrt, das mythische Restpotential muss durch metanarrative Elemente kompensiert werden.

\section{III}

Das zweite Beispiel: die Geschichte des Judas. Auch sie ist Zeugnis einer jahrhundertelangen Arbeit am Mythos. Schon an den Evangelien läßt sich eine zunehmende Dämonisierung der Figur ablesen - parallel zu derjenigen Satans. ${ }^{22}$ In der Patristik wird sie dann zum Gegenstand der Diskussion von Prädestination und Willensfreiheit, von Gnade und Verdammung, gleichzeitig auch zum Paradigma des ungläubigen Volkes Israel. ${ }^{23}$ Erzählerische Ausge-

22 PAgels (Anm. 18)

23 Zur Judasfigur im Neuen Testament und in der Alten Kirche WERNER VOGLER: Judas Iskarioth. Untersuchungen zu Tradition und Redaktion von Texten des Neuen Testaments und auBerkanonischer Schriften. Berlin 1983 (ThA 42); HANS-JOSEF KLAUCK: Judas - ein Jünger des Herrn. Freiburg 1987 (Quaestiones Disputatae 111); PERI TERBUYKEn/CHRISTIAN JOSEF KREMER: Judas Iskariot'. In: Reallexikon für Antike und Christentum. Lfg. 146 (1998), Sp. 142-160; zur Wirkungs'. skariot. Menschliches oder heilsgeschichtliches Drama. Hrsg. von HARALD WAGNER, Frankfurt a. M. 1985; BERNHARD DIECKMANN: Judas als Sündenbock. Eine verhängnisvolle Ge- 
staltungen begegnen seit dem 12. Jahrhundert, und auch sie sind mehr als bloß Ausmalungen eines in den Evangelien primär mit Blick auf Christus präsentierten Ereigniszusammenhangs. ${ }^{24}$ Sie rekurrieren wie die Vita Adae et Evae einerseits auf das christliche Verhältnis von Gnade und Verdammung, andererseits auf das mythische Skandalon von Verrat und Opfer. Ihr Kontext sind die in jener Zeit sich ausbreitenden Dramatisierungen, Narrativierungen und Mythologisierungen der christlichen Heilsgeschichte, die schnell auch die Volkssprachen erfassen. Ihr Bezugspunkt ist aber auch die sich in der gleichen Zeit vollziehende Neuaufnahme des Ödipus-Mythos, der so umerzählt wird, dass auf die Vorgeschichte der Passion Christi ein neues Licht fallen kann. ${ }^{25}$

Die älteste überlieferte lateinische Version ist am deutlichsten der ÖdipusGeschichte verpflichtet. Ein Sohn aus wohlhabender Jerusalemer Familie wird mit durchbohrten Unterschenkeln ausgesetzt, weil seinem Vater in einer Traumvision verheißen wurde, das Kind werde ihm nach dem Leben trachten. Von Hirten aufgefunden, wächst Judas in Scarioth heran und tritt in die Dienste des Königs Herodes. Als er für diesen aus einem fremden Garten Früchte besorgen soll, erschlägt er, ohne es zu wissen, den eigenen Vater und wird von Herodes ebenfalls unwissentlich der eigenen Mutter vermählt. Sie erkennt ihn an einer Narbe, er wendet sich reumütig von ihr ab und Jesus zu, der ihn unter seine Jünger aufnimmt. Hier wird er jedoch zunächst zum Dieb, sodann zum Verräter und schließlich zum von Reue gepackten Selbstmörder. Eine zweite Version reichert dieses Gerüst durch weitere, teils biblische Erzählmotive an. Der Traum wird nun wie in der Vita Adae et Evae der Mutter zugeschrieben. Die Aussetzung erfolgt - wie bei Moses - in einem Korb auf dem Meer. Neu

schichte von Angst und Vergeltung. München 1991; CHRISTFRIED BÖTRICH: Judas Iskarioth zwischen Historie und Legende. In: Gedenkt an das Wort. Festschrift für WERNER VOGLER zum 65. Geburtstag. Hrsg. von CHRISTOPH KÄHLER, Leipzig 1999, S. 34-55.

24 WiLHELM CREIZENACH: Judas Iscarioth in Legende und Sage des Mittelalters. In: Beiträge zur Geschichte der deutschen Sprache und Literatur 2 (1876), S. 177-207; E. K. RAND: Mediæval Lives of Judas Iscariot. In: Anniversary Papers by Colleagues and Pupils of GEORGE LYMAN KitTredGe, Boston 1913, S. 305-316; PaUll Franklin Baum: The Mediaeval Legend of Judas Iscarioth. In: Publications of the Modern Language Association 31, N. S. 24 (1916), S. 481-632; ELIAS VON STEINMEYER: Die Historia apocrypha der Legenda aurea. In: Münchener Museum für Philologie des Mittelalters 3 (1917), S. 155-166; PAUL LEHMANN: Judas Ischariot in der lateinischen Legendenüberlieferung des Mittelalters. In: DERS.: Erforschung des Mittelalters II. Stuttgart 1959, S. 229-285; FRANZ JOSEF WORSTBROCK: ,Judaslegende'. In: Verfasserlexikon. Die deutsche Literatur des Mittelalters $4\left({ }^{2} 1983\right)$, Sp. 882-887; DIECKMANN (Anm. 23), S. 23-121, 329-346

25 LEOPOLD CONSTANS: La légende d'œdipe. Etudiée dans l'antiquité, au moyen-âge et dans les temps modernes, en particulier dans le roman de Thèbes. Paris 1881; LowELL EDMUNDS: Oedipus. The ancient legend and its later analogues. Baltimore, London 1984; CHRISTOPH HU BER: Mittelalterliche Ödipus-Varianten. In: Festschrift WALTER HAUG und BURGHART WACHINGER. Tübingen 1992, S. 165-199. FRITZ PETER KNAPP: legenda aut non legenda [...]. In: GRM 53 (2003), S. 133-154 ist auch: Judas wird zu einer Insel getrieben und dort von der Königin als eigenes Kind aufgezogen. Als ihr ein leiblicher Sohn geboren wird und er von der eigenen Findlingsexistenz erfährt, erschlägt er wie Kain den Jüngeren. Nach Jerusalem zurückgekehrt, tritt er dann nicht in die Dienste des Herodes, sondern des Pilatus: Die beiden Geschichten wurden, wie wir noch sehen werden, auch in der Überlieferung häufig verknüpft.

Das Judasleben scheint auf die Frage zu reagieren, wie es dazu kommen konnte, dass einer aus dem Kreis der Jünger, also aus der nächsten Nähe des konte, des zugleich Ausgezeichneten und Ausgegrenzten, des Protagonisten, der dazu auserkoren Ausgezeichneten und Ausgegrenzten, des Protagonisten, der dazu auserkoren ist, dem Sohn Gottes den entscheidenden Vinne HYAM MACCOBYs ein Heschte zur Geschichte christlicher Heilserneuerung und zeichnet einerseits den Weg ins Verderben in mythischen Konstellationen nach, führt andererseits vor, dass selbst der größte Sünder, durch Vatermord und Inzest befleckt, gerettet werden kann - bzw. könnte, wenn er nicht neuerlich auf die Bahn des Unheils einschwenkte. Seit Augustinus wurde dies so gedeutet, daß die entscheidende Sünde des Judas nicht sein Vatermord, nicht der Verrat gewesen sei, sondern die zum Selbstmord führende Verzweiflung. ${ }^{27}$

Die Judas-Vita zielt indes nicht so sehr auf die desperatio als auf den doppelten Umschlagsmoment am Ende: die barmherzige Aufnahme und dann folgende definitive Ausschließung aus dem System der Gnade. Während die erste einen radikalen biografischen Bruch zu signalisieren scheint, stellt die zweite die biografische Kontinuität wieder her. Zugleich ergibt sich eine Spannung zwischen der Geltung und der Überwindung des mythischen Musters. Die Folie der Ödipus-Geschichte dient zunächst dazu, das Judasleben unter das Zeichen der Unentrinnbarkeit zu stellen. Die anfängliche Traumvision etabZeichen der Unentrinnbarkeit zu stellen. Die anfangliche Traumvision etabschicksalhafte Dimension des Geschehens und trägt gleichzeitig dazu bei, sie zu erfüllen. Am Ende jedoch dient die Abblendung der Folie der ÖdipusGeschichte dazu, das Geschick als scheinbar doch nicht unentrinnbares zu zeigen und im nächsten Atemzug wiederum die Scheinbarkeit hervorzuheben. Auch in der Abblendung bleibt also das mythische Muster präsent - als transformiertes: Die auf Unausweichlichkeit und Selbsterfuillung setzende Logik des Mythos wird aufgehoben durch die auf Barmherzigkeit und Gnade basierende Logik des Ethos, die ihrerseits aufgehoben wird durch die von Providenz und Sinntotalität geprägte Logik des Heilsplans, welche nun aber selbst mythische Züge trägt.

26 HyAm MACCOBY: Der Heilige Henker. Die Menschenopfer und das Vermächtnis der Schuld (engl. 1982). Stuttgart 1999.

27 FrIEDRICH OHLY: Der Verfluchte und der Erwählte. Vom Leben mit der Schuld. Opladen 1976 (Rheinisch-Westfälische Akademie der Wissenschaften. Vorträge G 207). 
Die Schlechtigkeit des Verräters und die Güte des Erlösers sind damit gleichermaßen gesichert, allerdings auf Kosten einer unauflöslichen Ambivalenz. Je nach Perspektive erscheint Judas als tragisch (Mythos), schändlich (Ethos) oder notwendig (Heilsplan), wobei sich das, was handlungsstrukturell aufeinander folgt, in den Semantiken der Texte wiederum überlagert. Schon die älteste Version kündigt eingangs die Geschichte dessen an, der malus in orte, peior in vita, pessimus in fine gewesen sei. Die Zeichen, unter denen der Lebenslauf steht, sind klar. Die Möglichkeit, dass sich die Frevel durch Reue und Buße schließlich in einen exemplarischen Heilsgewinn verwandeln, erscheint von vornherein als unwahrscheinlich. Das heißt aber auch: Die theologische Figur der immer möglichen Rettung und die narrative Logik des zu erwartenden Untergangs bringen sich nicht zur Deckung. Der Text muss behaupten, dass es eine Chance gebe, auch wenn es sie de facto im vorliegenden Fall nicht gibt und auch gar nicht geben darf. Eben dies aber, dass Judas als Verräter verdammenswert und als Instrument zur Erfüllung des Heilsplans notwendig ist, lässt sich auf der Textoberfläche nicht explizit zur Sprache bringen. Sowenig wie der Teufel in der Adamsgeschichte kann Judas im Passionsgeschehen einfach als Erfüllungsgehilfe Gottes erscheinen. Er ist deshalb böse und doch nicht ganz böse. Er agiert prototypisch und wird doch mit individuellen Zügen versehen ${ }^{28}$ Er behält handlungslogisch und theologisch eine Freiheit, die erzähllogisch und heilsgeschichtlich eine scheinbare ist, als scheinbare im Text aber nur durch Einspielung einer antiken Schicksalsmacht und durch die Anverwandlung des mythischen Musters (Determination zum Unheil) markiert werden kann. Daraus erklärt sich die schwankende Beurteilung der Judasfigur nicht erst in modernen Adaptationen ${ }^{29}$ Schon in manchen mittelalterlichen Versionen - so der der Legenda aurea - wiederholt sich nach dem Verrat die Reue. Judas wirft die 30 Silberlinge in den Tempel zurück, bevor er sein schreckliches Ende findet, und selbst diesem Ende konnte noch ein Moment der Barmherzigkeit eingeschrieben werden: Die Brandan-Legende berichtet von Brandans Begegnung mit dem Verdammten, der dank Gottes Erbarmen jeweils in der Nacht zum Sonntag von seinen Höllenqualen befreit ist. ${ }^{30}$ Der Dominikaner Vinżenz Ferrer war unter anderem deshalb in einen Häresieprozess verstrickt, weil er in einer Predigt von 1391, ältere Traditionen aufnehmend, erzählt haben soll, Judas habe nach dem Verrat bereut und versucht,

28 Vgl. JUTTA EMING: Judas als Held. Formen des Erzählens in der mittelalterlichen Judaslegende. In: ZfdPh 120 (2001), S. 394-412.

29 Vgl. KIM PAFFENROTH: Judas. Images of the Last Disciple. Louisville 2001. Populärwissenschaftliche Versuche zur Rehabilitierung des Judas gibt es zahlreiche, z. B. GERT BUCHHEIT: Judas Iskarioth. Legende - Geschichte - Deutung. Gütersloh 1954; WILLIAM KLASSEN: Judas. Judas Iskarioth. Legende - Geschichte - Deutu
Betrayer or Friend of Jesus? Minneapolis 1996.

30 Paull Franklin Baum: Judas' Sunday Rest. In: Modern Language Review 18 (1923), S. 168-182.
Jesus um Vergebung zu bitten, sei aber am Kalvarienberg durch die Menge nicht bis zu ihm vorgedrungen. Nach dem Selbstmord habe sich die Seele zum Kreuz aufgemacht, Vergebung erlangt und den Weg ins Himmelreich genommen. ${ }^{31}$ Die Momente der Reue und Gnade stehen in Kontrast zu den Momenten, in denen das Böse durchbricht, und sie ermöglichen es, den mythischen Absolutismus der Prädestination abzuschwächen und den Eindruck zu kaschieren, die Welt sei nur Bühne des göttlichen Heilsplans. Schon Jacobus de Voragine, der die Judas-Geschichte in der seines Nachfolgers, des Apostels Mathias, versteckte, war sich ihres beunruhigenden Potentials bewusst und zog ihre Wahrheit in Zweifel. ${ }^{32}$

Das beunruhigende Potential liegt nicht zuletzt darin, dass in der Frage, was einen der Jünger dazu gebracht habe, Jesus zu verraten, offensichtlich noch die ganz andere Frage steckt: was Gott dazu gebracht habe, seinen Sohn für die von ihm selbst geschaffene Menschheit zu opfern. Die theologische Antwort bezog sich, wie bei Lutwin gesehen, in der Regel auf die unendliche Barmherzigkeit Gottes gegenüber den Menschen, seine Selbstoffenbarung in der Geschichte. So brisant und logisch angreifbar diese Antwort war, bot sie doch zumindest dem mittelalterlichen Christen einen unübersehbaren Vorteil: Sie ließ sich dahingehend verstehen, dass Gott durch seine Selbstoffenbarung den Menschen eine Möglichkeit eröffnet habe, die nicht von allen genutzt wurde, die eine entscheidende kulturelle und religiöse Differenz begründete. Sosehr, aufs Ganze der Heilsgeschichte gesehen, der Alte Bund als Vorstufe und Grundlage des Neuen galt, sosehr galt, historisch-zeitgeschichtlich gesehen, die gegenwärtige Judenheit als verblendet und vom Heil abgeschnitten. Das Judasleben liefert für diese Trennung eine Ätiologie, bezogen nicht auf das Verhältnis zwischen Jesus und der jüdischen Gemeinde, sondern auf den einzelnen, der im Mittelalter schon namentlich als Paradigma der Judenheit interpretiert wurde. Er nun, dieser einzelne, repräsentiert im Sinne GIRARDs den impliziten Sündenbock, dessen Geschichte mit jener des expliziten Sündenbocks Jesus so verknüpft wird, dass der Mythos des Opfers des Gottessohns ein Pendant im Gründungsmythos der christlich-jüdischen Differenz erhält. $^{33}$

31 Dinzelbacher (Anm. 23), S. 65; DieckManN (Anm. 23), S. 139f.; PAfFenroth (Anm. 29), S. $120 \mathrm{f}$.

32 Jacobus de Voragine: Legenda aurea. Lateinisch-deutsch. Hrsg. und übersetzt von RAINER NICKEL, Stuttgart 1988 (Reclam UB 8464), S. 178-185.

33 RENÉ GIRARD: Das Heilige und die Gewalt. Freiburg 1987, Frankfurt a. M. 1992; DERS.: Das Ende der Gewalt. Analyse eines Menschheitsverhängnisses. Freiburg i. Br., Basel, Wien 1983; DERS.: Ausstoßung und Verfolgung. Eine historische Theorie des Sündenbocks. Frankfurt a. M. 1992 u. ö.; DERS.: Ich sah den Satan vom Himmel fallen wie ein Blitz. Eine kritische Apologie des Christentums. München 2002. 
Judas ist wie der Satan der Adamsgeschichte eine Figur der Nähe. ${ }^{34} \mathrm{Er}$ kommt aus Jerusalem, ist kein Fremder, sondern ein Vertrauter: von Christus mehr geschätzt als andere (diligebatur pre ceteris) heißt es in der zweiten lateinischen Fassung, vnserm herrn so gehaim vnd so lieb, dass er zum Verwalter der Almosen wurde, heißt es im Schaffhausener Judasleben. ${ }^{35}$ Es gibt Hinweise, dass im Kontext der Evangelien Judas sogar noch als Bruder Jesu galt. ${ }^{36}$ Auserwählt, dem Opfer den Weg zu bereiten und selbst ausgestoßen zu werden, ist also einer, der aus dem innersten Kreis kommt und diesen zugleich vertritt - gerade auch in seinem Verrat. BLUMENBERG hat ihn als den vielleicht konsequentesten Vertreter der messianischen Ungeduld verstanden, die sich auch bei anderen Jüngern äußere, am deutlichsten in der dreifachen Verleugnung des Petrus. ${ }^{37}$ Das Judasleben stellt zumindest in seinen ältesten Versionen diesen Zusammenhang nicht explizit her. Es beschränkt sich auf die Lebensgeschichte, die erst am Ende in die biblische Geschichte einmündet und dabei ihre Peripetien findet. Diese Beschränkung begründet zugleich die mythische Dimension eines Textes, der im Wesentlichen zeigt und nicht deutet, verborgene Hintergründe der neutestamentlichen Heilsgeschichte aufdeckt und doch auch im Mysteriösen belässt: ,nichts ist verhüllt, was nicht enthüllt, und nichts verborgen, was nicht bekannt werden wird" - die Worte Christi aus der Aussendungsrede (Mt 10,26) stehen am Beginn der ältesten Version, doch die Enthüllung erfolgt im mythischen Gewand.

Andere Versionen gehen andere Wege. Sie trennen explizit zwischen biblischem und außerbiblischem Teil des Judaslebens, integrieren dieses aber auch in den vollständigen Ablauf der Passionsgeschichte oder fügen noch weiteres Material, etwa zur Situation des Judas in der Hölle, hinzu. Verbreitet ist, wie angedeutet, die Verknüpfung mit der Pilatusgeschichte, die auch Johannes Rothe, der thüringische Chronist, bietet. ${ }^{38}$ Rothes volkssprachiges Kompendium gibt sich als Auszug aus einem größeren Werk und konzentriert sich auf vier Themen: Leben des Judas, Erfindung des Geldes und Geschichte der 30 Silberlinge, Leben des Pilatus, Zerstörung Jerusalems. Das Ganze wirkt auf den ersten Blick disparat. Auf den zweiten zeigen sich zahlreiche Korrespondenzen. Judas und Pilatus sind durch ihr Zusammentreffen in Jerusalem hand-

34 Als ,Spiegelfigur' versteht ihn ALBRECHT KOSCHORKE: Die Heilige Familie und ihre Folgen. Frankfurt a. M. 2000, S. 85-88.

35 OHLY (Anm. 28), S. 142.

36 MACCOBY (Anm. 26), S. 202-207; BERNhARD DieCKMANN: Judas als Doppelgänger Jesu? Elemente und Probleme der Judastradition. In: Dramatische Erlösungslehre. Hrsg. von JÓZEF NIEWIADOMSKI und WOLFGANG PALAVER, Innsbruck 1992 (Innsbrucker theologische Studien 38), S. 227-242.

37 BLUMENBERG (Anm. 18), S. 167

38 Johannes Rothes Passion. Mit einer Einleitung und einem Anhange. Hrsg. von ALFRED HEIN. RICH, Breslau 1906 (Germanistische Abhandlungen 26); vgl. VOLKER HONEMANN: ,Rothe'. In: Verfasserlexikon. Die deutsche Literatur des Mittelalters 8 ('1992), Sp. 277-285. lungsweltlich verbunden. Sie sind aber auch strukturell verbunden: Auch der römische Statthalter ist ein unter besonderen Vorzeichen geborenes Kind. Auch er tötet seinen Spielkameraden, den legitimen Sohn des Herrschers. Auch er endet im Selbstmord. Auch er ist ein Instrument in dem das Opfer des Gottessohns ermöglichenden Bedingungsgefüge und zugleich ein Instrument für die an Umbruchsstellen orientierte Heilsgeschichte. Verbindet sich mit Judas der Ursprungspunkt der Verblendung des jüdischen Volkes, so verbindet sich mit Pilatus der Ursprungspunkt der Christianisierung des römischen Weltreichs. $^{39}$

Details kommen dazu: die Geldgier der beiden, die ihren historischen Hintergrund erhält in der als Scharnier zwischen den Lebensläufen dienenden Genealogie des Geldes. Unter Ninus wurde von Trare, dem Vater Abrahams, das erste gleichmäßige Münzgeld erfunden, von dem der Erfinder selbst 30 Silberlinge als Lohn behielt. Diese Silberlinge wechselten im Folgenden durch Vererbung, Verkauf und Schenkung zwischen den Familien und Völkern und blieben doch, dank göttlicher Lenkung, immer zusammen: Abraham kauft mit ihnen den Acker, in dem Adam und Eva begraben liegen, vom Verkäufer gelangen sie an seinen Neffen, von ihm als Brautgabe an die Hismaheliten, dann an einen Kaufmann, der Joseph in Ägypten seinen Brüdern abkauft, dann von diesen an den Pharao, von ihm an Moses, dessen Frau und Töchter, schließlich an die Königin von Saba, die das Geld der Tempelkasse in Jerusalem stiftet, von wo Nabuchodonosor es nach Babylonien mitnimmt und einem arabischen König schenkt. Aus dem Orient bringen dann die Heiligen Drei Könige die Silberlinge wieder mit und schenken sie Maria, die sie dem Tempel stiftet, von wo sie als Lohn an Judas kommen, der sie aber reumütig wieder in den Tempel wirft, wo man beschließt, von dem Geld einen Acker zu kaufen, der als Begräbnisstätte für Pilger dienen soll. Am Ende des Textes, im Kontext der Zerstörung des Tempels, ist nochmals darauf Bezug genommen: So wie Jesus um 30 Silberlinge verraten wurde, so werden nun 30 gefangene Juden um jeweils einen Pfennig verkauft. ${ }^{40}$

39 Überblick zu den Pilatuslegenden bei JOACHIM KNAPE: ,Pilatus'. In: Die deutsche Literatur des Mittelalters 7 ('1989), Sp. 669-682. Zur Pilatusfigur JEAN-PIERRE LÉMONON: Ponce Pilate: documents profanes, Nouveau Testament et traditions ecclésiales. In: Aufstieg und Niedergang der römischen Welt. Geschichte und Kultur Roms im Spiegel der neueren Forschung. Tl. II: Principat. Bd. 26 (1. Teilbd.) Religion. Hrsg. von WolfGANG HAASE, Berlin, New York 1992, S. 741-778; BETTINA MATTIG-KRAMPE: Das Pilatusbild in der deutschen Bibel- und Legendenepik des Mittelalters. Heidelberg 2001; ANDREAS SCHEIDGEN: Die Gestalt des Pontius Pilatus in Legende, Bibelauslegung und Geschichtsdichtung vom Mittelalter bis in die frühe Neuzeit. Frankfurt a. M. 2002 (Mikrokosmos 68).

40 Vgl. auch LEOPOLD KRETZENBACHER: „Verkauft um dreißig Silberlinge“. Apokryphen und Legenden um den Judasverrat. In: Schweizerisches Archiv für Volkskunde 57 (1961), S. 1-17. MARJATTA WIS: Die dreißig Silberlinge. In: Neuphilologische Mitteilungen 71 (1970), S. 699-709; BLUMENBERG (Anm. 18), S. 186-191; DieCKMANN (Anm. 23), S. 107-118. 
Die Prinzipien, um die es Rothe geht, sind deutlich: einerseits der göttliche Plan in der menschlichen Geschichte, andererseits der Verrat der Juden. Der göttliche Plan wird am scheinbar Nebensächlichen sichtbar gemacht. Die Zirkulation der Silberlinge als eines paradigmatischen Kulturprodukts enthüllt Heilsgeschichte in nuce: der Weg des Volkes Israel, der Übergang vom Alten zum Neuen Bund, die Beziehung zwischen Urmenschenpaar und Neuem Menschen - die Genealogie erzählt, im weiten Bogen zwischen den beiden Äckern und der dreimaligen ,Einkehr' des Geldes im Tempel, von den verschlungenen Wegen des Heils. Das verbindet sie mit den Geschichten von Judas und Pilatus. Auch diese spielen ihre Rolle im Heilsplan, eine verwerfliche und doch notwendige. Die verwerfliche auszumalen lässt Rothe keine Möglichkeit aus: Er schildert den beständigen Konflikt zwischen Pilatus und den Juden und zeigt dadurch beide in negativem Licht. Die notwendige bleibt auch bei ihm überwiegend implizit; nur im Blick auf die Geschichte der Silberlinge macht er die göttliche Providenz explizit. Das ist kein Zufall: Eben dort, wo die Heilsgeschichte an einem auratischen Objekt betrachtet wird, wo das mythische Prinzip zu dominieren scheint, wo vorgefuihrt wird, wie ein Ursprung über die Zeiten hinweg seine materielle Präsenz behält, dort wird die theologische Sicherung wirksam, die das mythische Schema durch providentielle Geschichtsmächtigkeit überformt.

Rothes Text ist in dieser Hinsicht ein Lehrstück. Seine vier Teile sind so um Leben und Passion Christi herum geordnet, dass sie diese nur en passant streifen und doch konturieren - durch Geschichten des Davor und des Danach, Geschichten, die die Größe des Heilswerks gerade im Blick auf die hervortreten lassen, die sie nicht begreifen und doch ermöglichen. Obschon der thüringische Chronist die Ereignisse historisch präzise situiert, zielt er nicht schlicht auf die Historisierung, sondern in perspektivischer Auffächerung auf den Mythos der notwendigen Negativität. Er zeichnet sich selbst dort ab, wo die traditionelle theologische Hermeneutik im Vordergrund steht, wo also beispielsweise die in der Geschichte implizierte Parallele zwischen Judas und Moses expliziert wird. Rothe entfaltet diese Parallele systematisch im Blick auf die Jugendgeschichte der Figuren, ihre Bedeutung für das jüdische Volk und ihre Rolle im Heilswerk. Er bezieht den Verräter Christi typologisch auf eben den, der im Mittelalter meist selbst als Typus Christi galt, und stellt ins Zentrum den Gedanken: was der eine der beiden gotis botin (v. 275) den Juden gewonnen habe, habe der andere verwirkt. Beide sind sie also Repräsentanten entscheidender Punkte in der Geschichte des Alten Bundes, und beide sind sie bezogen auf den Heilsbringer Christus - wobei auch hier die Funktion des Judas für die beginnende Geschichte des Neuen Bundes unausgesprochen bleibt. Der Mythos der notwendigen Negativität schreibt sich fort in den Konstellationen, hier in jener Dreieckskonstellation, die auch Judas in mehrfacher Hinsicht ans Heilswerk bindet.
Diese Fortschreibung dehnt sich auch auf die Pilatus-Geschichte aus. Rothe erzählt von den Schwierigkeiten, die sich nach dem Tod des römischen Statthalters mit dessen Leiche ergeben. Zunächst wirft man sie in die Rhone, wo aber die Dämonen ihr Spiel mit ihr treiben, Stürme verursachen und Schiffe zum Untergang bringen. Sodann versucht man sie bei Lausanne tief unter der Erde zu begraben, erneut mit negativen Folgen: Die Dämonen lassen Steine umherfliegen, Hagel und Unwetter über die Felder kommen. Schließlich versenkt man sie auf dem Grund eines Gebirgssees, doch kommt es weiterhin zu Unruhe, Unwettern und Todesfällen. Der Herzog von Österreich lässt ein Kloster in der Nähe bauen und die Mönche durch ihre Gebete der Macht der Dämonen entgegenwirken. Die Gefährdung indes bleibt - bis in die eigene Gegenwart hinein, wie Rothe betont.

Es geht hier um mehr als nur eine geschichtsschreiberische Namensätiologie des bei Luzern gelegenen Pilatusberges, der schon im Mittelalter als mons Pilati bekannt war. ${ }^{41}$ Es geht darum, die beständige Gefährdung des Menschen durch das Böse zu zeigen - ein Böses, das in der Leiche des Pilatus einen klaren Ursprung und Bezugspunkt hat, damit aber auch eben jene Gegenwärtigkeit besitzt, die für mythisches Erzählen wichtig ist. Die eine Brücke zwischen Einst und Jetzt genügt zu zeigen: Die Geschichte ist nicht vergangen, sie wirkt fort, weil das Negative, heilsgeschichtlicher Narrativik zufolge, zwar im paradigmatischen Opfer um seinen Universalitätsanspruch gebracht, nicht aber gänzlich überwunden wurde. In Judas und Pilatus wiederholt sich das mit dem Engelsturz angebrochene heilsgeschichtliche Drama und sind zugleich die Bedingungen für dessen Lösung entworfen. Aber eben nur die Bedingungen. Da die Lösung selbst vorerst ausbleibt, braucht es des Mythos, um von dem zu erzählen, das bis zum Ende der Zeiten, wenn der Heilsplan Gottes auch den Menschen zugänglich würde, eine narrative Evidenz beanspruchen kann, die, so supplementär die Geschichten auch sein mögen, durch keine theologische Stringenz auszulöschen ist.

\section{IV}

Texte wie diese zeigen: Man darf es sich nicht zu leicht machen mit der sogenannten christlichen Gefangenschaft des Mythos. ${ }^{42}$ Man sollte nicht darüber entscheiden wollen, ob ein Text noch oder schon nicht mehr ein Mythos sei. Der historischen Komplexität wird man dadurch nicht gerecht. Auch dort, wo die theologische Deutung, die historische Situierung, die didaktische Geste

${ }^{41}$ HERSCHEL: Zur Pilatussage. In: Anzeiger für Kunde der deutschen Vorzeit N. F. 11 (1864), Sp. 364-369; HEINRICH (Anm. 38), S. 86-88.

42 JAuSS (Anm. 11); Mythos in mythenloser Gesellschaft. Das Paradigma Roms. Hrsg. von FRITZ GRAF, Stuttgart, Leipzig 1993 (Colloquium Rauricum 3) 
dominieren, können mythische Elemente präsent bleiben - schon deshalb, weil das Verhältnis zwischen göttlichem Plan und menschlichem Handeln in seinem Kern mysteriös blieb, weil Bilder und Geschichten nötig waren zu zeigen, was diskursiv und begrifflich nicht genauso effektvoll zu erfassen war. Die Supplemente zur biblischen Heilsgeschichte stehen zwar in kommentierendem Verhältnis zu ihrem kulturellen Prätext, doch der Kommentar bedient sich seinerseits der Bilder, Geschichten und mythischen Absolutismen. Sie arbeiten zwar zweifellos in dem Sinne am Mythos, dass sie dessen Härten und Sprünge auszugleichen versuchen. Sie partizipieren aber auch an ihm, suchen seine Faszination in der Umschrift zu bewahren.

Dies allerdings vollzieht sich in durchaus unterschiedlicher Weise. Im Falle von Adam und Eva geht es um die Anfänge der Menschheitsgeschichte, von denen vor biblischem Horizont zu erzählen immer auch hieß, Kontinuitäten zu stiften dort, wo der biblische Text radikale Brüche gesetzt hatte: im Verhältnis zwischen dem paradiesischen und dem nachparadiesischen Zustand. Im Falle von Judas geht es um die Neuanfänge der christlichen Geschichte, von denen zu erzählen zugleich die Möglichkeit bot, den Ursprung einer radikalen kulturellen Differenz mit heilsgeschichtlicher Dignität zu versehen. In beiden Fällen ist die Erzählung geprägt von der Spannung zwischen dem göttlichen Wollen und der menschlichen Schwäche, zwischen der Macht des Bösen und seiner Domestizierung, zwischen der Erhabenheit des Ursprungs und der Distanz zu ihm. ${ }^{43}$ Und in beiden Fällen ist es die Kategorie des Opfers, der Preisgabe des Menschen an die Geschichte und der Erlösung aus ihr, die es erlaubt, Gott und Mensch in eine Beziehung zu setzen, die wiederum die jeweilige Erzählung, oszillierend zwischen Nachschrift, Umschrift und Neuschrift, performativ entfaltet.

Es dürfte wichtiger sein, diese Formen narrativer Vergegenwärtigung und performativer Entfaltung analytisch zu beschreiben, als Festlegungen vorzunehmen, wie auch immer abgeleitet, vermittelt und vermindert bestimmte mythische Restbestände seien. Mit der Distanz zu einer Theologie, die den wahren Glauben nur sichern zu können meinte, indem sie seine narrativen Verkleidungen in religiöse Botschaften zurückverwandelte, ${ }^{44}$ wird auch der Blick frei für die genuine Leistung des Unbegrifflichen, für das Zusammenspiel von Konkretem und Abstraktem, für die kulturelle Wirksamkeit des Ambivalenten. Die Arbeit am Mythos zu Ende zu bringen oder die Rede von der Arbeit am Mythos zu Ende zu bringen ${ }^{45}$ - das sind nicht die Alternativen für

43 Zur Paradoxie des Ursprungs KLAUS HEINRICH: Parmenides und Jona. Basel, Frankfurt a. M. 31992, S. 9-28: Die Funktion der Genealogie im Mythos.

44 Vgl. Anm. 12.

45 BlumenberG, Arbeit (Anm. 9), 291-326; Odo Marquard: Lob des Polytheismus. Über Monomythie und Polymythie. In: Philosophie und Mythos. Hrsg. von HANS POSER, Berlin, eine historische Kulturwissenschaft. Sie hat, ohne Denkgewohnheiten zu verfallen, deren Logiken zu rekonstruieren: Logiken des Sowohl-als-auch, des Hin und Her, des Gegen und Mit in ihrer jeweiligen Historizität. In diesem Sinne hat die Auseinandersetzung mit der Rolle des Mythischen im angeblich mythenfeindlichen Kontext erst begonnen.
New York 1979, S. 40-58; wieder in: O. M: Abschied vom Prinzipiellen. Philosophische Studien. Stuttgart 1981 (RUB 7724), S. 91-116. 